\section{Carmen Alemany Bay}

Profesora titular de literatura hispanoamericana de la Universidad de Alicante y directora del Centro de Estudios Iberoamericanos Mario Benedetti de la citada Universidad. Ha sido antóloga y editora de obras de Miguel Hernández, entre ellas, la Obra completa. Es autora de los libros La novelística de Carmen Martín Gaite. Aproximación crítica, Poética coloquial hispanoamericana, El meridiano intelectual en Hispanoamérica, Mario Benedetti, Residencia en la poesía: poetas latinoamericanos del siglo $X X$ y $L a$ narrativa de la alteridad en Améri ca Latina (a partir del boom). Ha publicado más de sesenta artículos sobre literatura hispanoamericana y otros sobre literatura española del siglo XX.
La forma externa del poema en la poesía chilena: de la vanguardia a los albores del siglo XXI

CARMEN ALEMANY BAY

\title{
LA FORMA EXTERNA DEL POEMA EN LA POESÍA CHILENA: DE LA VANGUARDIA A LOS ALBORES DEL SIGLO XXI
}

\author{
CARMEN ALEMANY BAY \\ Universidad de Alicante, España \\ carmen.alemany@ua.es
}

\section{RESUMEN}

La experimentación vanguardista en poesía se destacó por ofrecer formas de expresión externa que en mayor o menor grado cimentaron en la poesía posterior. En Chile, la poesía ofrecerá, a partir de la vanguardia y con Vicente Huidobro, numerosos ejemplos de renovación que intentarán rebatir el tradicional poder de la escritura en pro de la democratización de esta. Un cúmulo de propuestas que se incentivaron con Nicanor Parra y que seguirán con los neovanguardistas.

Palabras clave: poesía chilena, forma externa del poema, vanguardia, Vicente Huidobro, Nicanor Parra, Raúl Zurita, Juan Luis Martínez.

\section{ABSTRACT}

Vanguard poetic experimentation is is known for providing external forms of expression that shaped poetry of later periods in many ways. In Chile, after the vanguard and Vicente Huidobro, poetry offers many examples of renovation which attempt to contradict the traditional power of writing by its democraticisation. These proposals were initiated by Nicanor Parra and continued with the neovanguardists.

Key words: Chilenan poetry, poem format, vanguard, Vicente Huidobro, Nicanor Parra, Raúl Zurita, Juan Luis Martínez.

Reflexiones sobre la forma externa del poema en Hispanoamérica

Las vanguardias supusieron la traslación al terreno artístico de una nueva época en la que se prescindía del pasado y se proponían otras formas más acordes con el presente. Desde el rechazo a la tradición, la experimentación vanguardista en poesía se destacó por ofrecer formas de expresión externa que dejaban en un segundo plano los contenidos representativos; es decir, se pasó de la poesía entendida como vehículo de transmisión de sentimientos o estados de ánimo, a indagar en las posibilidades de la factura del poema y expresar, desde esta coyuntura, sus diferencias con la visión canónica de lo poético.

Los artificios literarios externos han existido de forma continuada a lo largo de toda la historia; sin embargo, en la vanguardia pasarán a primer orden: nuevos formalismos (entiéndase la utilización de variada tipografía o diversas disposiciones versales) que estarán abocados a un marcado visualismo que en 
ocasiones desembocará en la «geometrización» de la palabra. Más allá de la poesía en forma de collages o de caligramas, procedentes fundamentalmente de Stéphan Mallarmé y de Guillaume Apollinaire, y que poca trascendencia tendrán en la historia literaria -salvo como síntoma de una transformación social de la escritura-; los movimientos de vanguardia europeos, y específicamente los hispanoamericanos (creacionismo, ultraísmo argentino, estridentismo, etc.), dotaron al poema de una nueva factura que contrastaba con la línea métrica más tradicional: se prescindía de la estrofa y de la rima, y el verso derivaba hacia una libertad inusitada que se alimentaba de las rupturas sintácticas. De forma explícita, los vanguardistas pusieron en evidencia la crisis de la noción de ritmo, y también de la métrica, como vía por la cual distanciarse del discurso poético tradicional.

A esta línea experimental se uniría otra, quizá más decisiva por la trascendencia que tendrá en poéticas posteriores y no desligada totalmente de la primera, que será el intento de acercar la escritura a la oralidad real para con ello ofrecer una amplia libertad lectora. De este modo, y considerémoslo una variación de primer orden, prescindirán de los signos de puntuación en el poema dotando al discurso de sus propias pausas y sus propias caídas, como una llamada a recuperar la oralidad y dejar en manos del lector una modulación distinta.

Con estas innovaciones el discurso poético tenderá a lo fragmentario, alejándose así del discurso público -es decir, el canónicamente literario-y aproximándose al discurso real, al cotidiano. En su perpetua crítica a lo establecido la vanguardia logró con estos cambios evidenciar la crisis del discurso público por su falta de identificación con el discurso real.

Este conjunto de evoluciones poemáticas -que incluían también, por ejemplo, otras voces en el poema que se señalaban en ocasiones con diferente tipografía- involucraban la renuncia del poeta al solo vocal, al rechazo de la preeminencia de la voz poética en pro de la inclusión de la polifonía de voces. Quizá los propios creadores, y también la crítica, resaltaron lo más epidérmico de este proceso, los hallazgos caligramáticos, y no ahondaron suficientemente en lo que estas transformaciones implicaban: libertad para el creador, que ya podía prescindir de férreas normas compositivas, e indirectamente $-\mathrm{y}$ no por todos asumido- la negación del solipsismo verbal del poeta.

Como suele ser habitual en los movimientos artísticos, tras un periodo de expansión se pasa a la regresión. Fueron muchas las aristas, los despropósitos que se configuraron en el interior de los movimientos vanguardistas, y el peligro de caer en la caricatura era ya evidente; por lo que muchos de aquellos que la promovieron -Vicente Huidobro, César Vallejo, Pablo Neruda y tantos otros-, intuitivamente, se acercaron a nuevas formas poéticas que se encerrarían bajo el nombre de posvanguardia.

La posvanguardia asumirá con timidez los mejores logros vanguardistas concernientes a la forma externa del poema. Aunque advertido de estos mecanismos, y ante la incapacidad quizá de mostrar nuevas fórmulas estructurales, el poeta -apabullado por los acontecimientos históricos y sociales- se vuelca en los contenidos, y la poesía, atendiendo a estos, se fracciona en poéticas que asumen de forma radical lo humano y lo social. La poesía se ensimisma, pero no se abstrae, se vuelve solidaria, comprometida con el hombre. Se seguirá manteniendo la libertad del verso, que ya no rima ni se estrofa, la ruptura de la sintaxis y el pensamiento lógico; pero se prescindirá de otros abalorios externos. La ejemplificación es evidente, baste sólo remitirnos a Poemas humanos de César Vallejo o a la tercera Residencia en la tierra de Pablo Neruda para comprobar la humanización de lo poético.

La forma externa del poema en la posvanguardia -como ya advertimos- sufrió un notable retroceso. Quizá la explicación esté en lo que Octavio Paz dijo sobre este momento poético en Los hijos del limo:

No se trataba, como en 1920, de inventar, sino de explorar. El territorio que atraía a estos poetas no estaba afuera ni tampoco adentro. Era esa zona donde confluyen lo interior y lo exterior: la zona del lenguaje. Su preocupación no era estética; para aquellos jóvenes era, simultánea y contradictoriamente, un destino y una elección. Algo dado y algo que hacemos (1990, pp. 208-209).

Sin embargo, estas palabras no acaban de explicar la recatada factura de la poesía en estos años y la explicación podría estar, al menos en aquella escritura que se acerca más a lo social, en que el poeta, una vez asume la responsabilidad de una voz pública asocia
La forma externa del poema en la poesía chilena: de la vanguardia a los albores del siglo XXI

CARMEN ALEMANY BAY 


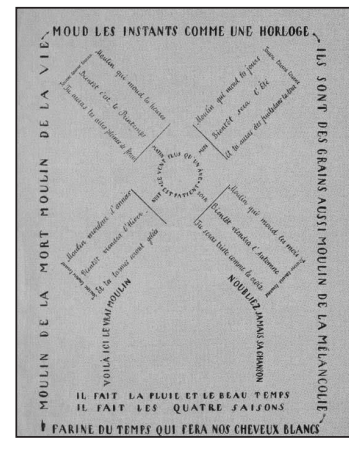

«Moulin» de Vicente Huidobro. ésta, en parte, a las formas antiguas, a la concepción tradicional de lo poético. Asimismo, y debido a la escasa distancia temporal, los nuevos formatos de escritura que propuso la vanguardia aún no se habían socializado.

Será en la segunda mitad de los años 50, y fundamentalmente en los 60 , cuando la poesía hispanoamericana empiece a ofrecer muestras de renovación. Frente a la convicción del tradicional poder de la escritura, numerosas voces apostarán -ante los cambios políticos y sociales tan intensos que se dieron en la primera mitad del siglo XX y la posterior impronta de los mass media en la vida cotidiana- por la viabilidad de incorporar la inventiva formal de raíz vanguardista en justa adecuación con los contenidos poéticos.

Así procederá el chileno Nicanor Parra desde su propuesta antipoética y el exteriorismo, encabezado por Ernesto Cardenal; y no muy lejos de similares planteamientos estarán los poetas coloquiales. Todos ellos, con mayores o menores diferencias, y sin olvidar la prioridad de lo que se comunica, emplearán los recursos heredados de las vanguardias para enriquecer el aspecto visual del poema en un afán de dinamizar el texto e, implícitamente, hacer al lector participe del hecho literario. La factura del poema se convierte en un espacio abierto que ayuda a reforzar la comunicación, por ende cada día más visual, rompiendo las diferencias tradicionales del discurso público y el discurso privado.

La forma externa del poema en la poesía chilena: de la vanguardia a los preludios de un nuevo siglo

De todos los países hispanoamericanos, es sin duda Chile la nación en la que los poetas pondrán una especial atención en la forma externa del poema, y quizás ello se explique en las siguientes palabras de María Nieves Alonso: «los poetas chilenos están permanentemente fugándose hacia lo otro, haciendo huir los sistemas del saber y del poder como se agujerea un tubo, atravesando el horizonte, penetrando en otros reinos» (2001, p. 11).

En los inicios de la vanguardia, surgirá una voz, la de Vicente Huidobro (1893-1948), que pergeñará una utopía artístico-poética, el creacionismo, en la que la forma externa del poema tendrá un lugar de excelencia. Su experimentalismo poético, en consonancia con las novedades científicas del momento, se modu- lará desde el poema pintado a la poesía visual, esta última ya presente en la revista Musa Joven en la que publicó su poema «Triángulo armónico»; composiciones visuales que seguirán presentes en Canciones en la noche. En Adán (poema) (1916), nuestro escritor dará muestras de la libertad inusitada del verso, que adquirirá una nueva concepción rítmica; también en esos años, con la publicación de El espejo de agua (1916), las disposiciones verticales o diagonales de algunos versos, los espacios en blanco de la página o el juego con diferentes tipografías serán novedades que se incrementarán en libros posteriores: desde Horizon carré (1917) hasta Automne régulier (1925). Nuevas percepciones poéticas, desplazamientos de sentido o recursos cinéticos, en pro de la estructura autónoma del poema, serán tangibles en estas obras que en definitiva serán ensayos de su obra mayor, Altazor (1931).

Publicado ya fuera de la vanguardia más eufórica, Altazor supuso el afianzamiento de una nueva forma de concebir lo poético pero también, y por lo que concierne a nuestro tema, la consolidación imperecedera del verso libre o la certeza de que este podía tener una longitud mucho más variable; una dialéctica de ruptura que en su caso comportó la destrucción del lenguaje denotativo, nuevos significados en la estructura lingüística, la desgramaticalización y hasta la misma disgregación del poema.

Vicente Huidobro, con estos avances, supo asentar sólidos cimientos que, en parte, cambiaron la concepción que se tenía de lo poético. Sus aportaciones no caerán en saco roto, sobre todo en su país, en Chile; y a lo largo del siglo XX, los poetas, de forma directa o indirecta, resurgirán continuadamente su legado. El cultivo de la forma externa del poema seguirá vigente.

En la posvanguardia, al igual que en otros países hispanoamericanos, las representaciones poemáticas sufrirán un retroceso tal y como es comprobable en las últimas entregas poéticas del propio Huidobro, El cindadano del olvido y Ver y palpar, ambos de 1941. Habrá que esperar unos años para que la poesía se desligue de su buscado recato, y quizás necesario, y que las composiciones asuman nuevamente que la forma externa del poema puede ofrecer renovadas versatilidades.

El nuevo adalid en esta empresa será Nicanor Parra (1914), el creador de la antipoesía. 
En sus Poemas y antipoemas (1954) intentará dinamitar las bases de lo canónicamente poético; entre ellas, separar la implicación del autor con el sujeto poético, y lo hará a través de un nuevo alfabeto que conlleva, entre otras cosas, un lenguaje coloquial insertado en poemas descoyuntados que nos recuerdan, aunque eliminando el referente pictórico, a los caligramas. Como ya observó Niall Binns, «sus discursos se encarrilan en un collage fragmentario de lenguajes de diversa procedencia, fiel y urgente reflejo de su propio caos interior. Por eso, las rupturas sintácticas y el aire onírico de las vanguardias perviven en los antipoemas» (2008, p. 788).

Una atención a lo externo del poema que tuvo su antecedente en 1952, cuando junto con Enrique Lihn y Alejandro Jodorowsky expusieron en El Quebrantabuesos un proyecto de poesía mural hecha a base de recortes de diario siguiendo las normas del collage. Años después, en el 58, Parra editó La cueca larga con imágenes de Nemesio Antúnez, anticipándose a una práctica cada día más presente en los libros de poemas.

En su avance hacia la diversificación de lo poético, Nicanor Parra editará, en 1972, Artefactos, conjunto de tarjetas postales sin numerar -y presentadas en una caja de cartón- en las que se combinaban códigos lingüísticos y visuales. Estos «artefactos» serán el resultado de la explosión del antipoema y, como explicara el autor, «los antipoemas estaban cargados de pathos y tenían que reventar»; no solo se atenúa el pathos si no que lo poético se equilibra con la imagen visual. En estos textos breves: «CUBA SÍ / YANKEES TAMBIÉN» o "LA IZQUIERDA Y LA DERECHA UNIDAS / JAMÁS SERÁN VENCIDAS», con claras influencias del graffiti y de la publicidad, el antipoeta intentó aproximar el lenguaje poético a otras vías de comunicación con la intencionalidad (democratización de la poesía) de que la poesía, insertada ahora en tarjetas, fuese patrimonio de todos y circulase como un objeto más de consumo. Para Niall Binns, «la revolución formal de Artefactos [...] se extendía a un cuestionamiento agresivo de la polarización ideológica del país» (2008, p. 793).

En 1975 dio a conocer, en la revista $M a-$ nuscritos de Santiago de Chile, sus «news from nowhere», textos de diversos formatos $\mathrm{y}$ entre los que destacan especialmente sus poema-dibujo. Una nueva renovación lle- gará en 1983 con Chistes par(r)a desorientar a la (policía) poesía -tarjetas ilustradas por diversos artistas en las que el chiste (como el artefacto) es reelaborado a partir de refranes, aforismos, sentencias, epigramas, slogans o titulares de periódico. Un nuevo paso, el de los chistes, hasta llegar a sus «trabajos prácticos» y a sus «artefactos visuales», rebautizados en otro momento como «obras públicas»; otra variación serán sus Fotopoemas (1988). Finalmente, lo poético se convertirá en Artefactos visuales expuestos en la Fundación Telefónica de Madrid en 2001.

La intención del poeta, en cualquier caso, será la de denotar las fallas de la poesía contemporánea y la necesidad de acompañarla de otros resortes más inherentes a los tiempos que corren. Con estos intentos, la poesía se va renovando con sus incesantes utopías que, sin renegar de lo clásico, se nutren de otros enseres como podemos comprobar en este primer soneto de «Los 4 sonetos del apocalipsis", pertenecientes a su libro Hojas de Parra (1985):

1

की

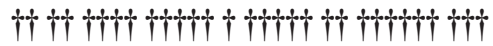

tht

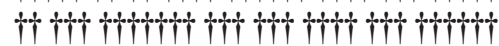

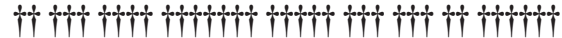

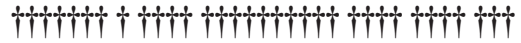

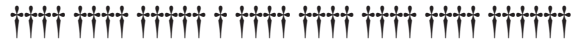

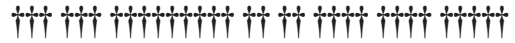

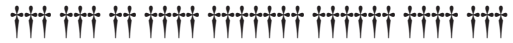

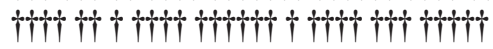 tht}

\section{Ot

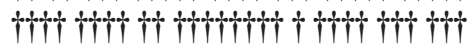

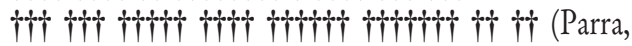 1989, p. 185)}

En estos años de producción del longevo Nicanor Parra, otros poetas chilenos intentarán a su modo seguir afianzando los instrumentos que contribuyen al enriquecimiento de la forma externa del poema. Recurrirán, con evidente frecuencia, a la supresión total o parcial de los signos de puntuación para que cada lector ajuste su propio ritmo de lectura, con lo que se le obliga a realizar otro tipo de

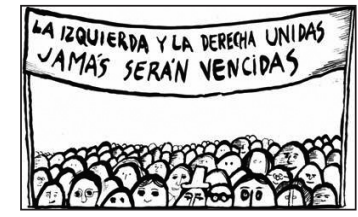

Artefacto de Nicanor Parra.

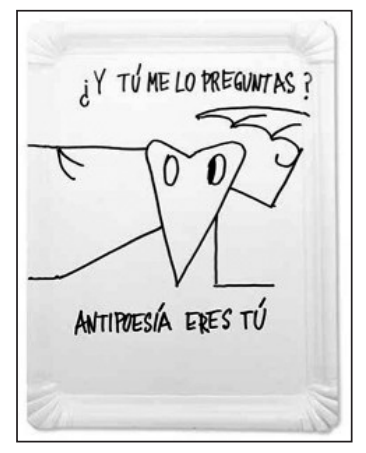

Artefacto visual de Nicanor Parra.

La forma externa del poema en la poesía chilena: de la vanguardia a los albores del siglo XXI

CARMEN ALEMANY BAY 


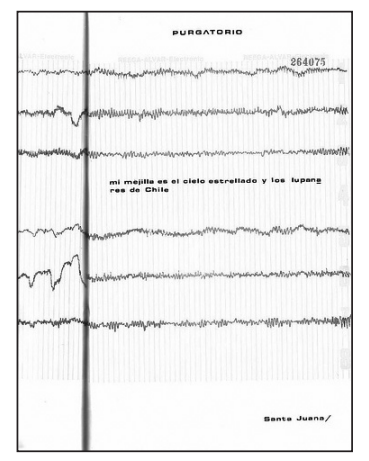

Encefalograma incluido en Purgatorio de Raúl Zurita.

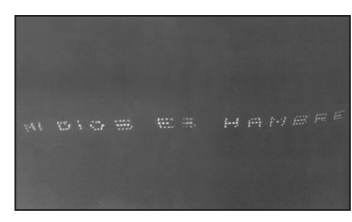

Versos de Zurita escritos sobre el cielo.

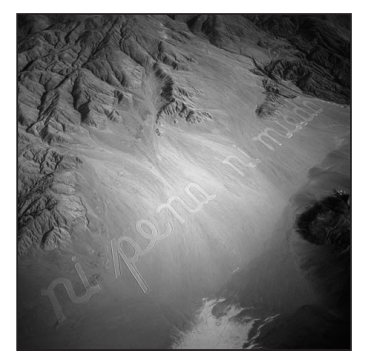

Verso de La vida nueva de Zurita.

1

Tal como recuerda Iván Carrasco, «La neovanguardia se inició hacia 1970 en el grupo del Café Cinema de Valparaíso, destacando Juan Luis Martínez, Raúl Zurita y James Cameron. Su postura era antitradicionalista, polémica, experimental, crítica, como la lírica vanguardista, de la cual adoptaron rasgos textuales como la ruptura de las normas convencionales en la construcción del poema mediante la incorporación de elementos no verbales de índole gráfica y objetal, de un sujeto despersonalizado, múltiple y escindido, víctima de las alienaciones, torturas y anormalidades de la época, de la expansión del significante fuera del espacio de la página» (1999, p. 161).

La forma externa del poema en la poesía chilena: de la vanguardia a los albores del siglo XXI

CARMEN ALEMANY BAY recitación, y no la puramente gramatical y correcta como preconiza la poesía canónica; sino una lectura que en cierto modo sea un simulacro de ficción de oralidad. Sin embargo, este será solo un mero procedimiento de los muchos que intentarán poner en práctica, fundamentalmente a partir de los años setenta, los llamados «neovanguardistas» encabezados por Juan Luis Martínez, Raúl Zurita y James Cameron, y a los que se unirán Gonzalo Millán, Floridor Pérez, Rodrigo Lira, Diego Maquieira, Clemente Riedemann o Elvira Hernández ${ }^{1}$. Como ha señalado Tomás Harris,

este grupo desplaza su textualidad del ámbito habitual de la poesía, hacia la experimentación que los relaciona con cierto sector de las vanguardias de comienzos de siglo (Artaud, Duchamp, Huidobro, Vallejo, Girondo) [...] en tanto experimentación a través del lenguaje incluyendo múltiples formas de codificación y lo que Luis Bocaz denomina fluidez semiótica, un esfuerzo por incorporar una pluralidad de códigos disímiles dentro del poema (2002, p. 305).

Todos ellos son poetas que en su juventud vivieron las fauces de la dictadura pinochetista, y quizá por ello se vieron en la necesidad de construir un discurso acusador que, creemos, tuvo también su incidencia en la factura del poema. La resistencia ante el poder establecido dejó su huella en el discurso poético. Siguiendo a Tomás Harris, «esta escritura experimental se constituye como una interrogante a la historia y la identidad chilena, dentro del contexto hispanoamericano y a la función del lenguaje en interacción de la producción textual, en un intento de reorganizarlo para constituirlo como un espacio de resistencia y trasgresión al sistema dominante. Una nueva aventura, una nueva mirada sobre el orden acostumbrado del lenguaje y el mundo poetizado» (2002, p. 307).

El libro Purgatorio (1979) de Raúl Zurita nos presenta en la portada una fotografía de la mejilla del escritor con los restos de una herida autoinfligida. Esta es solo una forma más de experimentación que se complementará con la incorporación de signos matemáticos y geométricos junto a signos verbales. No olvidemos que, tal como señala Julio Espinosa Guerra, la preocupación de los neovanguardistas «se centra en el esquema de comunicación y en los códigos mismos, ya no solo lingüísticos, pues incorporan imágenes y planteamientos científico / matemáticos en la elaboración de sus textos. También está muy presente la utilización de un lenguaje lógico y el problema del conocimiento versus el problema de la percepción sensorial e intuitiva. Privilegian la búsqueda de una imagen de contenido semiológico y la pérdida del ritmo si así se requiere» (2005, p. 30). Y así podemos comprobarlo en el poema que Zurita incluyó en la sección titulada «Mi amor de Dios»:

Áreas $\mathrm{N}=$ El Hambre de Mi Corazón
Áreas $\mathrm{N}=$ Campos $\mathrm{N}=\mathrm{El}$ Hambre de
Áreas $\mathrm{N}=$
Y el Hambre Infinita de Mi Corazón
En LOS CAMPOS DEL DESVARIO:
$\mathrm{N}=1$
La locura de mi obra
$\mathrm{N}=$
La locura de la locura de la locura de la
$\mathrm{N}$
«Los campos del hambre»

O los electroencefalogramas insertados en la octava y última sección, «La vida nueva». Estamos ante formas evolucionadas que proponen la mezcla de un lenguaje verbal con otro no verbal que surgieron ya en el proyecto estético de texto absoluto de Stéphan Mallarmé (en Igitur, 1869); pero en el caso de Zurita, opinamos, que se va más allá. El poema «La vida nueva», que abre Anteparaíso (1982), fue escrito en el cielo de Nueva York con el humo lanzado por cinco aviones en junio de 1982; y en el desierto chileno de Atacama grabó en 1993 el verso "ni pena ni miedo» que fue incorporado en La vida nueva (1994). Otra experiencia poética aparecerá en INRI (2003) con la incorporación de algunos versos escritos en Braille y dedicados a «aquellas víctimas a quienes la tiranía les sofocó la mirada».

La inserción de otros formatos en lo poético tiene como referencia obligada -en el ámbito chileno, pero también en el hispanoamericano- La nueva novela (1977) de Juan Luis Martínez. Para Elizabeth Monasterios, este libro es «un proyecto poético que cuestiona la primacía del sujeto en la filosofía occidental, desestabiliza la hegemonía del pensamiento racional en cuanto organizador del conocer; subvierte el concepto canónico de texto poético e involucra al lector en la producción y experiencia del acto creador» (1994, p. 868).

Nuevamente una fotografía en la portada será un reclamo para el lector, y en ella encon- 
tramos tanto el nombre del autor como el del editor, tachados. Otras fotografías, y algún dibujo, compartirán espacio junto a los textos poéticos; asimismo, la contratapa supondrá otra llamada de atención al lector a través de un diseño gráfico ${ }^{2}$. En su siguiente obra, La poesía chilena (1978), Juan Luis Martínez abogará por un objeto poético, una caja en forma de ataúd que lleva dentro una bolsa de plástico con tierra del valle central de Chile junto a los certificados de muerte y versos de Mistral, Neruda, Huidobro y del padre del escritor, Juan de Dios Martínez ${ }^{3}$.

En definitiva, una neovanguardia que nos remite a métodos tan primitivos como los signos o los dibujos que los prehistóricos escribieron en las paredes de una cueva, o las palabras que cualquiera de nosotros marcaríamos en la arena de una playa ${ }^{4}$. Con estas muestras poéticas podríamos afirmar, como sostenía Martin Heidegger, que la poesía no es ya la fundación del ser por medio de la palabra de la boca, sino que -por el contrario- es un «trabajo» con los restos, con los desechos: se trata de jugar y explorar con los límites de las palabras; $y$ en esta nueva dimensión, como hemos visto y continuaremos verificando, también jugará su papel la factura del poema.

La trasgresión de estos poetas chilenos es tal que merece ser reseñada por múltiples aspectos y no solo por romper los tabúes sobre la forma de las composiciones o que el papel pueda ser sustituido por formatos alternativos. A menudo, estas evidencias y reclamos -tal como ocurrió con los poemas caligramáticos de antaño $0^{5}$ no nos dejan ver con claridad la presencia de ciertos «utensilios» que colaboran en la significación activa del envoltorio del poema; aparejos que fueron novedad superlativa en la vanguardia, que se mantuvieron con timidez en la posvanguardia, y que en los años sesenta circularon con suficiente regularidad hasta hacer efectivo el paso del discurso privado al público. Nos referimos a la integración en el poema de diferentes tipos de letra, una disposición estrófica inesperada, el aislamiento o la separación de algunas palabras en el texto; o bien, recurrir sin reparos al uso de la vírgula (la barra), el paréntesis o notas al pie, etc. Estos poetas neovanguardistas, que según algunos «hacen una lectura posmoderna de las propuestas de las vanguardias europeas de principios de siglo y sus símiles en Latinoamérica» (Espinosa, 2005, p. 169), han logrado que aquello que fue novedad y rareza en tiempos de antaño se convierta en aportes necesarios para que el objeto poético pueda actualizarse en nuevas y sucesivas lecturas.

Además de los elementos señalados, y a los que recurriremos posteriormente, la libertad versal será otro de los atributos

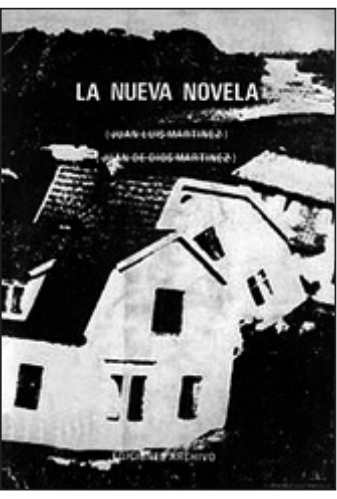

Portada La nueva novela de Juan Luis Martínez. de los que continua-

mente han hecho gala estos poetas: el verso puede llegar a tener una extensión inusitada (aunque esta no sería una particularidad exclusiva de los neovanguaristas); tanto es así, que la poesía rompe la barrera de los géneros y regulariza las distancias entre la poesía y la prosa. Así podemos visualizarlo en el poema de Elvira Hernández, "Carta de viaje», perteneciente a su libro con título homónimo y publicado en 1989:

En esa blancura torta boreal no encontrarán las huellas de mis extremidades.

No intento una plusmarca con las ruedecitas de mi trasero.

No soy el capitán Ávalos

No soy el Tiburón Contreras

Soy lengua ampollada por la electricidad $^{6}$

Esa implicación entre lo poético y lo prosístico -no olvidemos que el gran paso dado por la poesía de los últimos años es haber regularizado la distancia entre los géneros, fundamentalmente entre la poesía y la prosano solo se cercará en el espacio del texto sino que, en ocasiones, los títulos de los poemas simularán encabezamientos de tratados históricos con una finalidad totalmente paródica. Buen ejemplo de ello es el título de una de las composiciones de La nueva novela de Juan Luis Martínez: «Observaciones relacionadas con la exuberante actividad de la «Confabulación fonética» o «lenguaje de los pájaros» en las obras de J.-P. Brisset, R. Roussel, M. Duchamp y otros». Otros ejemplos en este mismo libro son «Fox Terrier desaparece en la intersección de las avenidas Gauss y Lobatchewski», de cierto carácter descriptivo; o
2

Como detalla Juan Herrera, «En la contratapa aparece una instrucción como encabezado: "Dibuje el contorno de cada cuarto incluyendo puertas y ventanas. Marque dos rutas de escape para cada miembro de su familia" y una nota en el margen inferior derecho: "Cada cuadradito equivale a $2 \mathrm{~cm}^{2 "}$. Entre la instrucción y la nota se inscribe un rectángulo de 16,3 centímetros de ancho por 22,1 centímetros de alto, que se encuentra reticulado, o sea, que conforma una red de 36 cuadrados de ancho por 48 de alto, los cuales están en razón de 3 es a 4. Los cuadrados son blancos y están delimitados por trazos o líneas negras» (2007).

3

Niall Binns nos recuerda que Juan Pablo Riveros en De la tierra sin fuegos (1986) «incorpora no solo citas, sino fotografías, notas y un glosario en su crónica de la desaparición de los ona y alacalufes en Tierra de Fuego relacionada con el autor con los que murieron allí durante la dictadura de Pinochet» (2008, p. 799).

Otras iniciativas de arte conceptual y poesía pueden apreciarse, aún dentro de Chile, en La nueva novela (1977) de Juan Luis Martínez; posteriormente, a partir de los años 80, Enrique Lihn trabajará en la incorporación de fotografías, plástica y videos a sus creaciones.

5

Algunos poetas chilenos como Eduardo Llanos, próximo a los neovanguardistas, en la parte más experimental de su obra seguirá haciendo uso de caligramas y poemas visuales.

6

Las referencias a los poemas que citaremos de ahora en adelante pertenecen a las antologías ya citadas de Julio Espinosa Guerra (2005) y María Nieves Alonso, Gilberto Triviños, Juan Carlos Mestre y Mario Rodríguez (tomos I y II) (2001); salvo alguna excepción que señalaremos.

La forma externa del poema en la poesía chilena: de la vanguardia a los albores del siglo XXI

CARMEN ALEMANY BAY 
«Silogismo homenaje a René Crevel "El más buen mozo de los surrealistas"», de carácter supuestamente laudatorio.

Como en numerosos textos prosísticos, el diálogo aparece como pieza fundamental y así se nos presenta, con algunos de sus ingredientes (la inclusión de comillas que potencian y simulan el carácter dialógico de lo poético), en «Un poco de calma» (perteneciente a Sabor a mí, de 1973), de Cecilia Vicuña; aunque en las respuestas se siga conservando la disposición versal:

$$
\begin{aligned}
& \text { y me decías: } \\
& \text { «no respondo si tú...» } \\
& \text { y yo te decía: } \\
& \text { «no me importa que no respondas } \\
& \text { porque no te voy a preguntar nada» }
\end{aligned}
$$

Recurrentemente, Raúl Zurita se acogerá a este tipo de diálogos, incluso con acotaciones, en, por ejemplo, «Allá lejos» de Anteparaíso. Por su parte, Juan Luis Martínez, en aquellas composiciones que llevan por título «La realidad», configura el espacio textual en bloques de preguntas y respuestas que se multiplican $\mathrm{y}$, como despiste para el lector, otros conjuntos son sustituidos por otros referentes de la comunicación:

\section{A. PREGUNTA:}

¿Qué es la realidad? ¿Cuál es la realidad?

RESPUESTA:

Lo real es sólo la base, pero es la base.

RESPUESTA:

Lo real es aquello que te chocará como realmente absurdo.

\section{B. AFIRMACIÓN:}

El ser humano no soporta mucha realidad.

Como nota final a la prosificación del texto poético, estarían las notas al pie, empleadas en ocasiones por estos escritores con claros fines paródicos. Estas nos ofrecen una información adicional para complementar o contrastar lo dicho en el texto principal: les sirven para pedir disculpas al lector, como en "Ars poetique» de Ricardo Lira; para hacer comentarios de poca trascendencia, en contraposición con lo establecido en los cánones de la prosística; o para incluir versos de otros poetas. Estos dos últimos casos pueden observarse en el poema «El angustioso caso de soltería» de Ricardo Lira en la única obra del autor y que se publicó tras su muerte, Proyecto de obras completas (1984). A ello también recurre Elvira Hernández en su poema «Letras y letrinas», perteneciente a Santiago Waria. Se incluyen en su propio texto las siguientes palabras de A. Artaud (la autora indica la autoría en nota al pie): «el alma no ha sido más que un viejo refrán» (en el texto aparece en letra negrita).

El avance prosístico de lo poético se ve acompasado por el afianzamiento de la oralidad. De este modo, la poesía presenta nuevas alternativas como la utilización del paréntesis (( )) que sirve para marcar cierto carácter polifónico: supone un añadido o un comentario a lo que se está diciendo desde un punto de vista externo, tal como sucede en el lenguaje oral. También, y como ahora veremos, puede servir como acotación; pero además, en estos versos de Juan Luis Martínez se hace uso de otros signos para acercar lo real a lo metafórico; y, en un triple salto mortal, que esas referencias se conviertan en literarias, en darianas concretamente:

$$
\begin{aligned}
& \text { (¿Y el signo interrogante de su cuello (?) ?: } \\
& \text { reflejado en el discurso del agua: } \quad \text { (¿) : es una } \\
& \begin{array}{l}
\text { errata) }
\end{array}
\end{aligned}
$$

También la oralidad nos ha demostrado que las pausas pueden no ser precisamente las convencionales, y es en este punto en el que el poeta introduce mecanismos formales que enfatizan otras visualizaciones que implicarán otra manera de ver la escritura, como el uso de la vírgula (/) entre fragmentos versales; tal como hicieron en repetidas ocasiones los llamados poetas coloquiales de los años 60 (Alemany, 1997, p. 133). A ello recurrirá con fruición Rodrigo Lira en algunas composiciones de su Proyecto de obras completas, en especial en «El espectador imparcial: una escrituración exasperada»:

\section{LOS QUE Vienen desde el siniestro costado/}

Acarrean -a tracción sanguínea-/

Una máquina/ que se desliza sobre rodillos

cilíndricos/ una armazón

De este modo se nos ofrece una marca de lectura que sirva de rectificación, de duda, o de complemento a lo dicho, o simplemente la sustitución de la tradicional coma (,) con el fin de causar un efecto inesperado. 
Otro procedimiento será el sangrado -o el espaciado- entre palabras que buscará no sólo diferenciar entre la pausa prosódica y la pausa gráfica, normalizando de este modo el conflicto entre la pausa prosódica y la psíquica; sino también convertir en menos violento el encabalgamiento y otorgarle más dinamismo al texto. Así, el espacio en blanco pierde el sentido de intervalo y se integra con valor propio, eliminando toda concepción simbólica o descriptiva de la escritura. El mismo Francisco Lira hará uso de este recurso en su «Ars poetique»; y Elvira Hernández en «M...», perteneciente a Santiago Waria (1992):

$$
\begin{aligned}
& \text { tanto amor o igual empuje } \\
& \text { tanto tanto tanto } \\
& \text { y nada }
\end{aligned}
$$

Asimismo, provocarán falsos encabalgamientos mediante el guión como ya hiciera Enrique Lihn en algunas de sus composiciones, en concreto en "Varadero de Rubén Darío»:

La acción, es un acto; la poesía una exigencia; una «revo-

lución permanente», un trabajo de los mil de-

monios (1969, p. 62)

Y a ello recurrirá también Rodrigo Lira en la ya mencionada composición «El espectador imparcial...».

La finalidad de estos mecanismos será incentivar otras lecturas más próximas a la intencionalidad psíquica, lo que sin duda aleja al poema de cualquier escritura canónica. Pero no lo olvidemos, semejantes arrojos provienen de ese gran atrevimiento que fue la vanguardia y en este caso, sin duda, de Vicente Huidobro. Nos bastaría visualizar el poema «Ars poetique, Deux» de Rodrigo Lira para comprobar la huella permanente del autor de Altazor.

Todos estos mecanismos contribuyen a la creación de una escritura pensada para la concepción visual, y de esta también se ha heredado la división estrófica inesperada. Se descoyunta el poema, aislando o separando algunas palabras, con el fin de que surja algún efecto en el lector; pero sobre todo para que el verso no sólo diga o sugiera, sino que exprese la sensación poética. En todos estos poetas neovanguardistas podemos encontrar numerosos casos, pero sírvanos de botón de muestra algunos fragmentos del poema «A modo de explicación» de Rodrigo Lira en el que el escritor, además, aprovecha esos desplazamientos inusitados para recurrir al anaforismo:

\section{Soplando trompetas tañendo campanas rezando en voz alta}

descansa

corriendo despacio por los arenales llorando miserias descansa

entonando un tango muriendo de a poco fumando cabañas

descansa

Frente a ese descoyuntamiento del poema encontraremos su reverso, que es la presencia en las composiciones de versos que se agrupan en bloques enumerados mediante números o letras. Quizás, en medio de la irracionalidad política que tuvieron que vivir estos poetas en su juventud, en medio de un mundo caótico, se vieron en la necesidad de reorganizar su mundo poético a través de mecanismos reconstructores. Algunos de sus poemas, influidos por la corriente estructuralista, se organizarán en series numeradas, como ejemplo los poemas de Raúl Zurita «El desierto de Atacama III» de Purgatorio, «Las playas de Chile V» o «Las utopías» (del que mostamos los primeros versos) ambos de Anteparaíso:

i. Todo el desierto pudo ser Notre-Dame pero fue el desierto de Chile.

ii. Todas las playas pudieron ser Chartres pero sólo fueron las playas de Chile.

iii. Chile entero pudo ser Nuestra Señora pero áridos estos paisajes no fueron sino los evanescentes paisajes chilenos

La inclusión de estos recursos formales contribuirá a una mayor polifonía del poema que supondrá en definitiva la democratización de lo poético, algo que evidentemente no se logró en los años veinte. Pero en la poesía, a diferencia de otros géneros, no existen grandes brechas; por ello los poetas, tal como hemos visto, seguirán manteniendo aquello que incorporó con audacia la vanguardia. Para Iván Carrasco,

la poesía neovanguardista se asemeja a su modelo vanguardista en la actitud rebelde y provocativa ante los valores y discursos de la tradición y el afán
La forma externa del poema en la poesía chilena: de la vanguardia a los albores del siglo XXI

CARMEN ALEMANY BAY 
de transformar la sociedad mediante la interacción arte-vida. Pero se diferencia en la radicalización de diversas estrategias y figuras, como la parodia, la distorsión de citas y de tópicos, la transtextualidad en sus variadas formas, el uso constante de la alusión referencial de tipo histórico y biográfico, la ampliación de la capacidad expresiva del verso, la frase y también del libro y del macrotexto, concebidos como significantes globales de la reflexión poética y la experiencia del mundo (1999, p. 161).

A ella se le debe en gran parte el uso de diferentes tipografías que tienen como finalidad que el poema se centre en la letra misma y en sus posibilidades artísticas, lo que supone una escritura pensada para una percepción global, visual. De ello podemos percatarnos en algunos versos de Vírgenes del sol inn cabaret (1986) de Alexis Figueroa, e incluso en los títulos de algunos poemarios de Cecilia Vicuña: PALABRARmás (1984) o QUIPOem (1997).

En definitiva, la continuidad en el cultivo de la factura del poema ha sido decisiva para seguir explorando en las posibilidades del texto poético; pero no en el sentido lúdico, estético y diferencial en el que incidió la vanguardia, sino en la activación del texto en verso (Alemany, 1997, pp. 127-141). La sensación de que las normas métricas son una sombra del pasado ha alcanzado definitivamente a la poesía; los cortes versales, por ejemplo, están más marcados por la velocidad que por el ritmo, y la cadencia es ya la de la oralidad. En este camino, que no es más que la continuidad de lo que se gestó en la vanguardia, los poetas no dejarán de alimentar la idea de que la arbitrariedad en la significación del lenguaje es un hecho, como también lo es el extrañamiento del habla.

Asentados ya en una sociedad global, donde la sombra de la posmodernidad asoma también en América Latina, el gran hallazgo, la identidad de la poesía actual, es la mezcla de códigos y el discurso poético se configura como un sistema de crítica a los registros establecidos. Un cúmulo de propuestas que convergen en pro de la construcción de una poética heterodoxa y que tendrá sus seguidores, también en Chile, en Nadia Pardo o en otros poetas como «Mardones, Cárcamo, que buscan variantes a la neovanguardia» (Carrasco, 1999, pp. 167-168).

La poesía hispanoamericana, fiel a su estilo de continua renovación, ha arbitrado con sabiduría todo el legado que acumuló la vanguardia y lo ha ido transformando y mutando hasta nuestros días, donde la factura del poema ha sabido equilibrar la importancia de los contenidos con las formas del poema.

\section{Bibliografía}

Alemany Bay, Carmen (1997), Poética coloquial hispanoamericana, Alicante, Publicaciones de la Universidad de Alicante.

Alonso, María Nieves; Triviños, Gilberto; Mestre, Juan Carlos; Rodríguez, Mario (2001), Informe para extranjeros. Antología de la poesía chilena contemporánea (tomos I y II), Colección Juan Ramón Jiménez de Poesía, Huelva, Diputación de Huelva.

Binns, Niall (2008), «Cincuenta años de poesía chilena», en Trinidad Barrera (coordinadora), Historia de la literatura hispanoamericana. Siglo $X X$, tomo III, Madrid, Cátedra, pp. 787-802.

Carrasco, Iván (1999), "Tendencias de la poesía chilena en el siglo XX», Anales de Literatura Hispanoamericana, 28, pp. 157-169.

Espinosa Guerra, Julio (ed.) (2005), Antología. La poesía del siglo XX en Chile, Madrid, Visor.

Harris, Tomás (2002), «La voz de los 80 (promociones poéticas 1979-1989)», en Kart Kohut y José Saravia (eds.), Literatura chilena boy. La difícil transición, Frankfurt/ Madrid, Vervuert, pp. 297-313.

Herrera, Juan (2007), "La nueva novela de Juan Luis Martínez: Poesía protohipertextual en el contexto de la videósfera» Acta Literaria, 35. Disponible desde internet en www.scielo.cl/scielo. php ? script $=$ sci_arttext $\&$ pid $=$ S0717 68482007000200002\&lng=es\&nrm=

Lihn, Enrique (1969), Escrito en Cuba, México, Ediciones Era.

Monasterios, Elizabeth (1994), «La nueva novela: el texto que ríe», Revista Iberoamericana, LX:168-169, pp. 859-872.

Parra, Nicanor (1989), Chistes para desorientar a la poesía (edición de María Nieves Alonso y Gilberto Triviños), Madrid, Visor.

Paz, Octavio (1990), Los hijos del limo, Barcelona, Seix Barral.

Fecha de recepción: 06/06/2011 Fecha de aprobación: 26/09/2011 